\title{
KAJIAN PENCEMARAN AIR TANAH OLEH LINDI DI SEKITAR TEMPAT PEMBUANGAN AKHIR SAMPAH AIR DINGIN KOTA PADANG
}

\author{
Yaumal Arbi ${ }^{1}$, Ronald Siregar ${ }^{2}$ dan Tri Padmi Damanhuri ${ }^{3}$ \\ ${ }^{1}$ Universitas Negeri Padang \\ ${ }^{2}$ Universitas Sumatra Utara \\ ${ }^{3}$ Institut Teknologi Bandung \\ E-mail: ${ }^{1}$ yaumalarbi@ft.unp.ac.id, ${ }_{2}{ }^{3}$ tripadmi@gmail.com
}

\begin{abstract}
Abstrak: Tempat pembuangan akhir Air Dingin Kota Padang operasionalnya menggunakan sistem Open damping. Terdapat perumahan penduduk pada radius $200 \mathrm{~m}$ dari TPA yang menjadikan air sumur dangkal sebagai sumber air utama dan perlu dilakukan permodelan menggunakan model Domenico and Scwartz untuk mengetahui sejauh mana penyebaran lindi pada air tanah. Parameter yang di simulasi meliputi Chemical Oxygen Demand (COD), Timbal $(\mathrm{Pb})$ dan Besi $(\mathrm{Fe})$. Dari hasil pengukuran lindi TPA melebihi baku mutu Kep. No. 51/MENLH/I0/1995 Fe 5,4 mg/L, Pb 0,85 mg/L dan COD $3400 \mathrm{mg} / \mathrm{L}$. Pengukuran kontaminan pada sumur warga di lakukan pada 3 sumur dengan jarak 300, 600 dan 900 meter dari TPA searah aliran air tanah. Hasil pengukuran parameter pada sumur warga menunjukan nilai COD yang tinggi. Simulasi $\mathrm{Fe}$ dan $\mathrm{Pb}$ yang berasal dari lindi telah menyebar $\pm 175 \mathrm{~m}$ dari TPA mengikuti aliran air tanah. Penyebaran kontaminan COD mencapai \pm 40 $\mathrm{m}$ arah longitudinal dan $\pm 200 \mathrm{~m}$ arah transversal. Prediksi Pencemaran $\mathrm{Fe}$ dan $\mathrm{Pb}$ pada air tanah terjadi 93 tahun yang akan datang dan mencapai jarak 312 meter dari TPA. Sedangkan konsentrasi COD mengalami fase steady state pada jarak 40 meter dari TPA.Tingginya nilai kontaminan COD yang terukur pada sumur warga di sekitar TPA Air Dingin Padang bukan disebabkan oleh pencemaran lindi TPA, namun disebabkan faktor lain seperti kandungan COD yang tinggi pada air tanah di sekitar lokasi TPA.
\end{abstract}

Kata kunci: TPA, besi, timbal, COD, model Domenico and Schwart.

\begin{abstract}
Air dingin landfills in Padang city operations using Open dumping system. There are residents in a radius of $200 \mathrm{~m}$ from the landfill that makes the water shallow wells as the main source of water and need to be modeled using the model of Domenico and Scwartz to determine the extent of the spread of leachate on groundwater. The parameters in the simulation include the Chemical Oxygen Demand (COD), Lead $(\mathrm{Pb})$ and iron (Fe). From the measurement results of landfill leachate exceeded the quality standard of Kep. No. 51/MENLH/IO/1995 Fe $5.4 \mathrm{mg} / \mathrm{L}, \mathrm{Pb} 0.185 \mathrm{mg} / \mathrm{L}$ and COD $3400 \mathrm{mg} / \mathrm{L}$. The measurements of contaminants in the wells is done at a distance of 3 wells with 300, 600 and 900 meters from the landfill in the direction of groundwater flow. The results of measurements of parameters in wells showed high value of COD. The simulation of Fe have spread \pm $150 \mathrm{~m}$ and $\mathrm{Pb}$ spread $\pm 250 \mathrm{~m}$ from the landfill following the groundwater flow. The spread of contaminants $C O D$ reaches $\pm 25 \mathrm{~m}$ longitudinal direction and $\pm 200 \mathrm{~m}$ transversal direction. The pollution prediction of $\mathrm{Fe}$ and $\mathrm{Pb}$ in groundwater will be occur in 80 years ahead and reach 312 meters from the landfill. While the COD concentration through a steady state phrase at 25 meters from landfill. The increasing of the contaminants COD values measured in wells around the landfill around Air Dingin Padang not caused by pollution of landfill leachate, but due to other factors such as high COD content in the groundwater around landfill sites.
\end{abstract}

Keywords: Landfill, Iron, Lead, COD, Domenico and Schwart model

PENDAHULUAN

Tempat pembuangan akhir (TPA) Air Dingin Kota Padang telah beroperasi sejak tahun 1986. Walaupun didesain dengan sistem Sanitary Lanfill, operasionalnya tetap menggunakan sistem Open damping . Lindi 
dari landfill seringkali berpotensi mencemari air tanah maupun air sungai ( $\mathrm{Lu}$ et al., 2008). Ketika lindi mencapai sumber air, maka dapat menyebabkan pencemaran pada sumber air tersebut (Aljaradin \& Peerson, 2012). Kontaminan terbawa oleh pergerakan air melalui tanah, mengkontaminasi tanah, air tanah, dan air sungai (Kassenga dan Mbuligwe, 2009).

Dearah sekitar TPA Air Dingin di Kota Padang mulai di padati oleh pemukiman penduduk. Berdasarkan SNI 19-2454-2002, kriteria jarak TPA ke perumahan terdekat lebih besar dari $500 \mathrm{~m}$. Namun pada kenyataanya terdapat perumahan pada radius $200 \mathrm{~m}$ dari TPA yang menjadikan air sumur dangkal sebagai sumber air utama. Dekatnya jarak TPA dengan perumahan, berkemungkinan akan mempengaruhi kualitas air sumur tersebut.

Pencemaran lindi terhadap air tanah disebabkan adanya rembesan lindi yang kemudian menyebar mengikuti aliran air tanah. Pada lingkungan tanah dan air tanah, proses transport yang utama adalah adveksi, difusi, disperse, adsorbsi (Bedient et al., 1999). Saat ini, model matematika untuk masalah kualitas air di sungai merupoakan lat yang efisien dalam manajemen sumber daya air (Benedini, 2011). Model matematika bermanfaat untuk pemanfaatan sumber daya air, mereduksi pembuangan dari sumber tertentu, estimasi dampak perubahan teknologi terhadap lingkungan(Arbi \& Aidha, 2017), pengembangan metode dan fasilitas pemantauan, dan manajemen pengelolaan kualitas lingkungan (Kachiashvili et al., 2009). Permodelan penelitian ini menggunakan solusi persamaan Domenico and Scwartz.Parameter yang menjadi fokus adalah Chemical Oxygen Demand (COD), Timbal $(\mathrm{Pb})$ dan Besi $(\mathrm{Fe})$.

\section{METODOLOGI}

\section{Lokasi penelitian}

TPA Air Dingin terletak di Air Dingin, Kecamatan Koto Tangah dengan luas 30,30 Ha. TPA Air Dingin ini digunakan oleh 11 kecamatan di Kota Padang dengan rata-rata jumlah timbulan sampah yang masuk per hari ke TPA Air Dingin tahun 2008 dari data Dinas Kebersihan dan Pertamanan (DKP) Kota Padang adalah sebesar 1.930,92 $\mathrm{m}^{3} /$ hari atau 317,37 ton/hari.

\section{Pengumpulan data primer}

Untuk mengetahui pengaruh air lindi TPA Air Dingin terhadap air tanah dangkal disekitarnya, sampling dilakukan pada lima lokasi yaitu air lindi TPA Air Dingin, sumur uji TPA Air Dingin, sumur tanah dangkal dan sumur kontrol.

\section{Aplikasi model}

Rancangan model analitik menggunakan solusi analitis Domenico and Schwartz (1990), model ini dikembangkan berdasarkan persamaan adveksi, dispersi dan reaksi sebagai berikut:

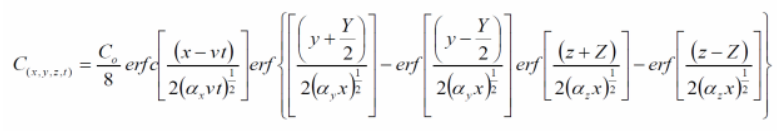

Persamaan 1

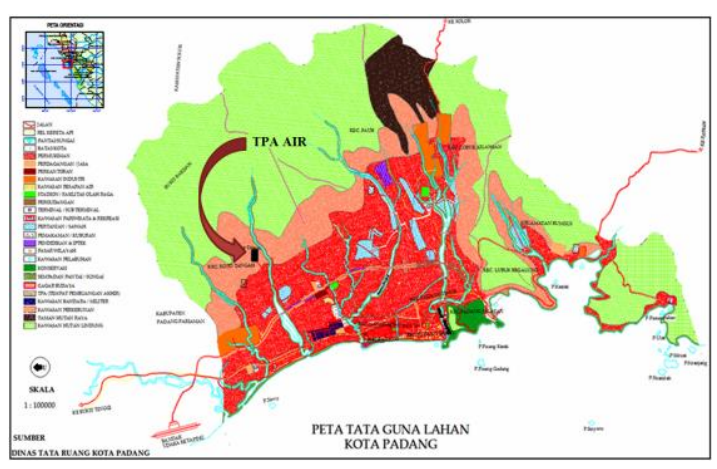

Gambar 1. Lokasi TPA Air Dingin

Sedangkan untuk senyawa nonkonservatif berdasarkan persamaan berikut:

$$
\begin{aligned}
& c_{(x, y, z, t)}=\left(\frac{C_{0}}{8}\right) \exp \left\{\left(\frac{x}{2 \alpha_{x}}\right)\left[1-\left(1+\frac{4 \lambda \alpha_{x} \frac{1}{v}}{v}\right)^{\frac{1}{2}}\right]\right\} \\
& \operatorname{erfc}\left[\frac{R x-v t\left(1+\frac{4 \lambda \alpha_{x}}{v}\right)^{\frac{1}{2}}}{2\left(R \alpha_{x} v t\right)^{\frac{1}{2}}}\right]\left\{\operatorname{erf}\left[\frac{\left(y+\frac{Y}{2}\right)}{2\left(\alpha_{y} x\right)^{\frac{1}{2}}}\right]-\operatorname{erf}\left[\frac{\left(y-\frac{Y}{2}\right)}{2\left(\alpha_{y} x\right)^{\frac{1}{2}}}\right]\right\} \\
& \left\{\operatorname{erf}\left[\frac{\left(2+\frac{2}{2}\right)}{2\left(\alpha_{2} x\right)^{\frac{1}{2}}}\right]-\operatorname{erf}\left[\frac{\left(2-\frac{2}{2}\right)}{2\left(\alpha_{2} x\right)^{\frac{2}{2}}}\right]\right\}
\end{aligned}
$$

Persamaan 2

Dimana C adalah konsentrasi kontaminan pada titik $\mathrm{x}$ dan waktu $\mathrm{t} ; \mathrm{C}_{0}$ merupakankonsentrasi kontaminan pada titik sumber yang di dapat kan dari pengukuran di lapangan; $\mathrm{R}_{\mathrm{f}}$ faktor retardasi; $\mathrm{V}$ adalah kecepatan air tanah / kecepatan 
kontaminan yang sudah dikoreksi dengan faktor retardasi; $\lambda$ koefisien transformasi laju orde satu $\left(1 / \mathrm{T}=(\ln 2) /\left(\mathrm{t}_{1 / 2}\right)\right.$, waktu $(\mathrm{t})$; $\mathrm{Y}$ lebar sumber pencemar; $\mathrm{Z}$ kedalaman sumber pencemar; $\alpha_{\mathrm{x}}$ dispersivitas longitudinal; $\alpha_{\mathrm{y}}$ dispersivitas traverse; $\alpha_{\mathrm{z}}$ dispersivitas vertical; $x$ jarak horizontal dari sumber dalam arah aliran air tanah; y jarak dari titik tengah sumber pencemar tegak lurus arah aliran; $\mathrm{z}$ jarak vertikal dari top akuifer.

\section{HASIL DAN PEMBAHASAN Titik Loksi Sampling}

Lokasi pengambilan sampel dilakukan di sekitar TPA Air Dingin Kecamatan Koto Tangah, Kota Padang. Sampel lindi diambil dari saluran penampungan lindi. Sampel Air tanah diambil pada sumur warga yang berada di arah utara dari TPA. Pengambilan sampel air tanah dilakukan pada 4 titik lokasi sampling.

Tabel 1. Lokasi pengambilan sampel lindi

\begin{tabular}{ccccc}
\multicolumn{5}{c}{ dan air tanah } \\
\hline Lokasi & Loordinat & Waktu & Elevasi \\
\hline & Lon & Lat & tanggal & mdpl \\
TPA & $100^{\circ} 22^{\prime} 53.325^{\prime \prime} \mathrm{E}$ & $0^{\circ} 49^{\prime} 75.518^{\prime \prime} \mathrm{S}$ & 041213 & 44 \\
Lokasi I & $100^{\circ} 23^{\prime} 6.7664^{\prime \prime} \mathrm{E}$ & $0^{\circ} 49^{\prime} 942336^{\prime \prime} \mathrm{S}$ & 041213 & 61 \\
Lokasi II & $100^{\circ} 22^{\prime} 34.476^{\prime \prime} \mathrm{E}$ & $0^{\circ} 49^{\prime} 905527^{\prime \prime} \mathrm{S}$ & 041213 & 39 \\
Lokasi III & $100^{\circ} 22^{\prime} 30.769^{\prime \prime} \mathrm{E}$ & $0^{\circ} 49^{\prime} 677373^{\prime \prime} \mathrm{S}$ & 041213 & 37 \\
Lokasi IV & $100^{\circ} 22^{\prime} 14.792^{\prime \prime} \mathrm{E}$ & $0^{\circ} 49^{\prime} 842423^{\prime \prime} \mathrm{S}$ & 041213 & 32 \\
\hline
\end{tabular}

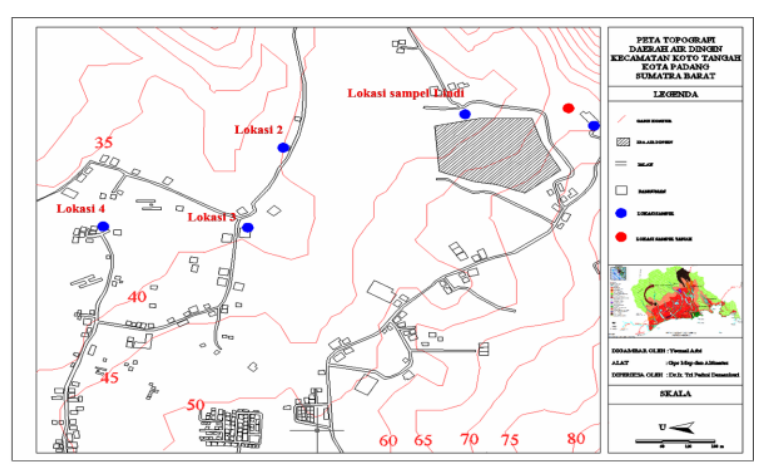

Gambar 2 Titik sampling

\section{Analisis Sampel Lindi}

Parameter fisik yang terukur adalah suhu $33^{\circ} \mathrm{C}, \quad$ DO 4,9 mg/l, pH 8,06, DHL $5,5 \mathrm{mS} / \mathrm{cm}$. Nilai $\mathrm{pH} 8,06$ menunjukan lindi bersifat basa dan masih memenuhi baku mutu Kep. No.51/MENLH/I0/1995. Suhu pada lindi cukup tinggi $\left(33{ }^{\circ} \mathrm{C}\right)$ akan mempengaruhi aktivitas mikroorganisme dalam penguraian bahanbahan organik.

Tabel 2. Karakteristik Air Lindi TPA Air Dingin

\begin{tabular}{lccc}
\hline Parameter & Satuan & $\begin{array}{c}\text { Kep. No. } \\
\text { 51/MENLH/I0/1995 }\end{array}$ & $\begin{array}{c}\text { Air } \\
\text { Lindi }\end{array}$ \\
\hline $\mathrm{pH}$ & - & $6-9$ & 8,06 \\
\hline $\mathrm{DO}$ & $\mathrm{mg} / 1$ & - & 2,5 \\
\hline Temperatur & $0 \mathrm{C}$ & 40 & 33 \\
\hline $\mathrm{DHL}$ & $\mathrm{mS} / \mathrm{cm}$ & - & 5,5 \\
\hline $\mathrm{BOD}_{5}$ & $\mathrm{mg} / 1$ & 150 & 351,4 \\
\hline $\mathrm{COD}$ & $\mathrm{mg} / 1$ & 300 & 3400 \\
\hline $\mathrm{TSS}$ & $\mathrm{mg} / 1$ & 400 & 710 \\
\hline $\mathrm{Fe}$ & $\mathrm{mg} / 1$ & 5 & 5,4 \\
\hline $\mathrm{Zn}$ & $\mathrm{mg} / 1$ & 10 & 0,03 \\
\hline $\mathrm{Pb}$ & $\mathrm{mg} / \mathrm{l}$ & 0,1 & 0,185 \\
\hline
\end{tabular}

\section{Analisis Sampel Air Tanah}

Analisis sampel air tanah dilakukan laboratorium untuk menentukan parameter $\mathrm{Fe}, \mathrm{Pb}$, dan $\mathrm{COD}$ yang terkandung pada sumur air tanah dangkal.

Berdasarkan Tabel 3, kandungan besi (Fe) di sumur warga berkisar 0,407 - 1 $\mathrm{mg} / \mathrm{L}$. Nilai tersebut melebihi baku mutu menurut Keputusan Menteri Kesehatan No 907 tahun 2002 yaitu sebesar 0,3 mg/L. Nilai besi (Fe) terbesar terdapat pada sumur yang berjarak $300 \mathrm{~m}$ dari TPA dan semakin menurun seiring bertambahnya jarak TPA dari sumur warga.

Tabel 3. Karakteristik Air tanah

\begin{tabular}{lccc}
\hline Titik sampling & \multicolumn{3}{c}{ Parameter } \\
\cline { 2 - 4 } & $\begin{array}{c}\mathrm{Fe} \\
(\mathrm{mg} / \mathrm{L})\end{array}$ & $\begin{array}{c}\mathrm{Pb} \\
(\mathrm{mg} / \mathrm{L})\end{array}$ & $\begin{array}{c}\mathrm{COD} \\
(\mathrm{mg} / \mathrm{L})\end{array}$ \\
\hline Lokasi I & 0,407 & 0,039 & 56 \\
\hline Lokasi II & 1 & 0,066 & 75 \\
\hline Lokasi III & 0,778 & 0,053 & 60 \\
\hline Lokasi IV & 0,593 & 0,033 & 48 \\
\hline \multicolumn{1}{c}{ Batas } & maksimum & COD & menurut
\end{tabular}

Keputusan Menteri Kesehatan No 907 tahun 2002 yaitu sebesar $10 \mathrm{mg} / \mathrm{L}$, sedangkan rentang konsentrasi yang terdeteksi di sumur warga adalah $48-75 \mathrm{mg} / \mathrm{L}$. Konsentrasi COD tertinggi terdapat pada sumur yang berjarak $300 \mathrm{~m}$ dari TPA.

Konsentrasi $\mathrm{Pb}$ yang melewati baku mutu terdeteksi pada sumur warga dengan jarak 300, 600 dan $900 \mathrm{~m}$ dari TPA. Baku mutu $\mathrm{Pb}$ menurut Menteri Kesehatan No 907 tahun 2002 adalah 0,01 mg/L. 


\section{Analisis Sampel Tanah}

Analisis karakteristik tanah dilakukan untuk menentukan parameter fisik tanah dan pergerakan kontaminan dalam tanah. Sampel tanah di ambil pada kedalaman \pm 1 $m$ di hulu TPA Air Dingin, sehingga di dapatkan tanah yang belum terkontaminasi oleh lindi TPA. Selanjutnya sampel tanah di analisis di Laboratorium. Hasil yang di dapatkan dapat dilihat pada Tabel 4.

Tabel 4. Hasil Uji Karakteristik Tanah

\begin{tabular}{lcc}
\hline \multicolumn{1}{c}{ Hasil Uji Karakteristik Tanah } & Satuan & Nilai \\
\hline Porositas $(\mathrm{n})$ & - & 0,52 \\
Kadar air $(\theta)$ & $\%$ & 19,5 \\
Rapat jenis tanah $\left(\rho_{\mathrm{b}}\right)$ & $\mathrm{kg} / \mathrm{m}^{3}$ & 1,97 \\
Konduktivitas Hidrolis $(\mathrm{K})$ & $\mathrm{m} / \mathrm{hari}^{2}$ & 0,11 \\
Lempung & $\%$ & 69 \\
Pasir & $\%$ & 8 \\
Kerikil & $\%$ & 5 \\
Liat & $\%$ & 18 \\
\hline
\end{tabular}

Jenis sampel tanah yang diambil merupakan Silt Loam. Nilai konduktivitas hidrolis yang di dapat yaitu sebesar 0,11 $\mathrm{m} /$ hari.

\section{Arah dan Kecepatan Air tanah}

Pengukuran muka air tanah beretujuan untuk penentuan gradien hidrolik. Gradien hidrolik menunjukkan perubahan tekanan dalam aquifer yang menghasilkan aliran air tanah, dilakukan pengukuran ketinggian muka air tanah pada 3 buah sumur yang berjarak 300, 600 dan $900 \mathrm{~m}$ dari TPA.

Tabel 5. Hasil Pengukuran Tinggi Muka Air Tanah

\begin{tabular}{cccccc}
\hline Lokasi & $\mathrm{X}(\mathrm{m})$ & $\mathrm{Y}(\mathrm{m})$ & $\begin{array}{c}\text { Elevasi } \\
\text { tanah }\end{array}$ & $\begin{array}{c}\text { muka } \\
\text { air }\end{array}$ & $\begin{array}{c}\text { Head } \\
\text { hidrolis }\end{array}$ \\
\hline $\begin{array}{c}\text { Sumur } \\
1\end{array}$ & 653041 & 9908974 & $39 \mathrm{~m}$ & $3 \mathrm{~m}$ & $36 \mathrm{~m}$ \\
\hline $\begin{array}{c}\text { Sumur } \\
2\end{array}$ & 652926 & 9908609 & $37 \mathrm{~m}$ & $2,6 \mathrm{~m}$ & $34,4 \mathrm{~m}$ \\
\hline $\begin{array}{c}\text { Sumur } \\
3\end{array}$ & 652444 & 9908614 & $32 \mathrm{~m}$ & $2,8 \mathrm{~m}$ & $29,2 \mathrm{~m}$ \\
\hline
\end{tabular}

Dengan nilai koefisien konduktivitas hidrolik (K) dan porositas diperoleh dari hasil uji karakteristik fisik tanah dengan nilai masing-masing sebesar $0,11 \mathrm{~m} / \mathrm{hari}$ dan 0,52. Penentuan kecepatan air tanah menggunakan metode yang diperkenalkan oleh Pinder et al., (1981), maka kecepatan aliran air tanah diperoleh sebesar 0,053 $\mathrm{m} /$ hari.

\section{Model Penyebaran Kontaminan}

Pemodelan penyebaran kontaminan lindi menggunakan pengembangan solusi analitik Domenico. Model ini mampu menggambarkan persebaran kontaminan dalam air tanah. Tabel 6 menunjukan asumsi yang dipergunakan dalam model Domenico and Schwartz.

Tabel 5. Parameter yang diperlukan dalam model (Domenico and Schwartz, 1990)

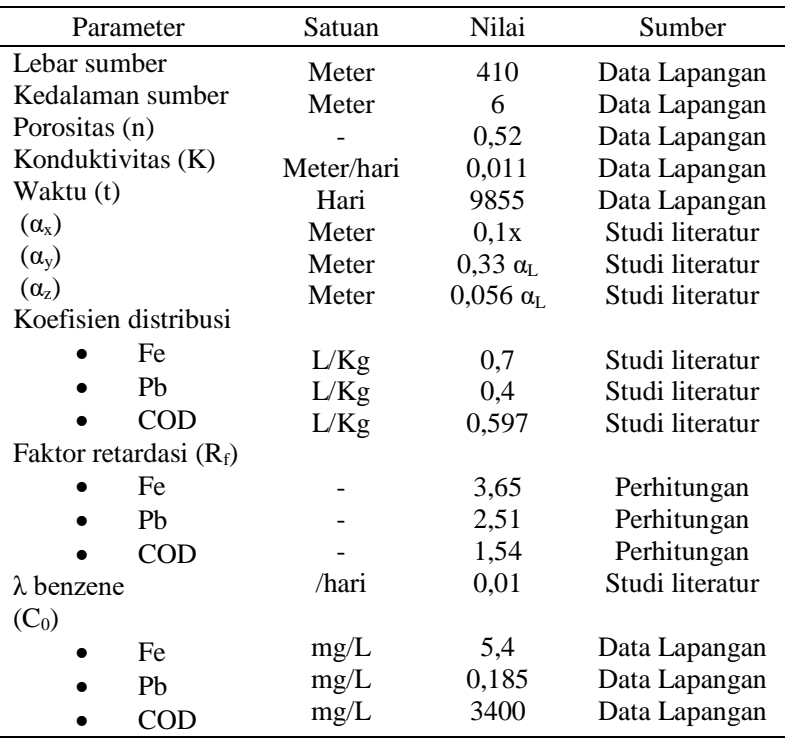

Kedalaman dan lebar sumber didapatkan dari data lapangan. Nilai porositas dan konduktivitas berdasarkan analisis karateristik tanah yang dilakukan. NIlai waktu 27 tahun diasumsikan sama dengan umur TPA. Kondisi awal kotaminan $\mathrm{Fe} 5.4$ $\mathrm{mg} / \mathrm{L}, \mathrm{Pb} 0,185 \mathrm{mg} / \mathrm{L}$, dan COD $3400 \mathrm{mg} / \mathrm{L}$ Nilai dispersivitas transfersal $\left(\alpha_{\mathrm{x}}\right)$, dispersivitas transfersal $\left(\alpha_{\mathrm{y}}\right)$, dan dispersivitas vertikal $\left(\alpha_{\mathrm{z}}\right)$ menggunakan literatur menurut Tong et al, 2013. Koefisien distribusi $\left(\mathrm{K}_{\mathrm{d}}\right)$ yang digunakan berasal dari range $\mathrm{K}_{\mathrm{d}}$ Allison et al (2005). Sehingga $\mathrm{K}_{\mathrm{d}}$ yang dipilih untuk $\mathrm{Fe}$ da $\mathrm{Pb}$ adalaah 0,7 dan $0,4 \mathrm{~L} / \mathrm{Kg}$. Sedangkan koefisien distribusi yang digunakan untuk COD adalah koefisien distribusi senyawa Benzene , dan nilai $\lambda$ Benzene $=0,01 /$ hari (DeVaull et al., 1997). $\mathrm{R}_{\mathrm{f}}$ untuk Fe 3,65, $\mathrm{R}_{\mathrm{f}}$ $\mathrm{Pb}$ 2,51 dan $\mathrm{R}_{\mathrm{f}}$ COD 1,54. Dengan menggunakan Persamaan 1 untuk kontaminan $\mathrm{Fe}, \mathrm{Pb}$ dan Persamaan 2 untuk 
kontaminan COD dilakukan simulasi model dengan bantuan program Matlab.

\section{Model Penyebaran Kontaminan Besi (Fe)}

Simulasi model dilakukan secara dua dimensi dengan waktu 27 tahun sesuai dengan umur TPA Air Dingin. Gambar 3 menunjukan simulasi model dua dimensi penyebaran Fe pada air tanah dangkal. Dari simulasi model 2D dapat disimpulkan pencemar menyebar mencapai jarak $\pm 150 \mathrm{~m}$ dari TPA. Hasil simulasi belum menjangkau jarak titik observasi terdekat yaitu $312 \mathrm{~m}$.

Gambar 4 menunjukkan prediksi simulasi Fe satu dimensi ketika usia operasional TPA 27, 50, 80, dan 120 tahun. Konsentrasi dan jarak penyebaran diperidiksi meningkat sesuai bertambahnya usia operasional TPA. Hasil simulasi menunjukan pada waktu 120 tahun dari mulai TPA beroperasi, kontaminan $\mathrm{Fe}$ melebihi baku mutu pada jarak $312 \mathrm{~m}$.

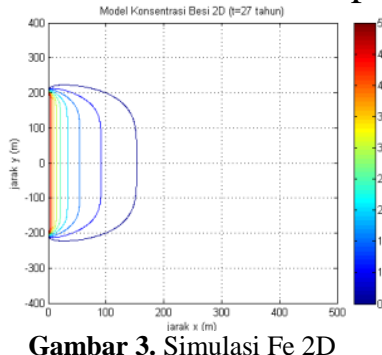

Gambar 3. Simulasi Fe 2D

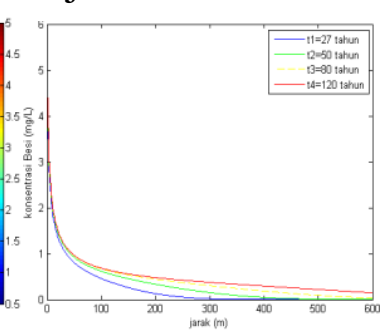

Gambar 4. Simulasi 1D Fe

Model Penyebaran Kontaminan Timbal (Pb)

Gambar 5 menunjukan hasil simulasi persebaran kontaminan $\mathrm{Pb}$, dapat dilihat penyebaran kontaminan $\mathrm{Pb}$ mencapai jarak $175 \mathrm{~m}$. Gambar 6 menunjukkan prediksi simulasi $\mathrm{Pb}$ satu dimensi. Hasil prediksi menunjukan konsentrasi $\mathrm{Pb}$ akan melebihi baku mutu menurut Keputusan Menteri Kesehatan No 907 tahun 2002 pada waktu 120 tahun . yang akan datang sebesar 0,0108 mg/L pada jarak $312 \mathrm{~m}$ dari TPA.

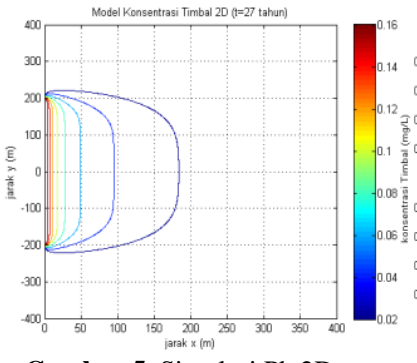

Gambar 5. Simulasi $\mathrm{Pb} 2 \mathrm{D}$

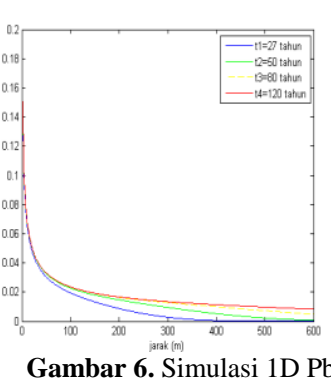

Gambar 6. Simulasi 1D Pb

\section{Model Penyebaran Kontaminan COD}

Gambar 7 menunjukkan simulasi model dua dimensi COD pada saat ini ketika usia operasional TPA 27 tahun diketahui bahwa penyebaran kontaminan COD mencapai \pm $100 \mathrm{~m}$ arah longitudinal dan $\pm 200 \mathrm{~m}$ arah transversal. Konsentrasi COD hasil observasi pada sumur warga yang berkisar $48-75 \mathrm{mg} / \mathrm{L}$ tidak berasal dari lindi TPA.

Gambar 8 dapat dilihat bahwa COD mengalami fase steady state pada jarak 40 meter dari TPA, sehingga tidak akan terjadi perubahan konsentrasi kontaminan. Proses steady state lebih cepat terjadi dibandingkan dengan senyawa konservatif.

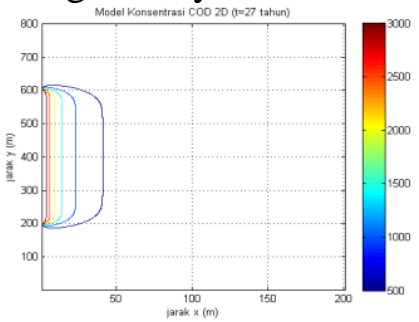

Gambar 7. Simulasi COD Gambar 8. Simulasi 1D COD

\section{KESIMPULAN}

Konsentrasi $\mathrm{Fe}, \mathrm{Pb}$ dan $\mathrm{COD}$ pada air tanah di sekitar lokasi TPA tidak memenuhi baku mutu yang di tetapkan oleh Keputusan Menteri Kesehatan No 907 tahun 2002. Konsentrasi $\mathrm{Fe}, \mathrm{Pb}$ dan $\mathrm{COD}$ menurun seiring dengan bertambahnya jarak dari TPA. Tingginya nilai kontaminan yang terukur pada sumur warga disekitar TPA Air Dingin Padang bukan disebabkan oleh pencemaran lindi TPA, namun disebabkan faktor lain seperti kandungan $\mathrm{Fe}, \mathrm{Pb}$ yang tinggi pada air tanah di sekitar lokasi TPA.

Kontaminan $\mathrm{Fe}$ telah menyebar sejauh $150 \mathrm{~m}$ dan kontaminan $\mathrm{Pb}$ menyebar sejauh $175 \mathrm{~m}$ dari TPA mengikuti aliran air tanah. 
Penyebaran kontaminan COD mencapai 40 $\mathrm{m}$ arah longitudinal.

Prediksi Pencemaran Fe akan melewati baku mutu pada waktu 120 tahun semenjak TPA beroperasi. Prediksi Pencemaran $\mathrm{Pb}$ akan melewati baku mutu 93 tahun yang akan datang dengan konsentrasi 0.0108 $\mathrm{mg} / \mathrm{L}$ pada jarak $312 \mathrm{~m}$ dari TPA. Prediksi Pencemaran COD mengalami fase steady state pada jarak 40 meter dari TPA, sehingga tidak akan terjadi perubahan konsentrasi kontaminan.

\section{Daftar Pustaka}

Aljaradin, M. Persson, K.M. (2012) : Environmental Impact of Municipal Solid Waste Landfills in Semi-Arid Climates-Case Studies-Jordan. The Open Waste Management Journal P: 28-39. Bentham Science.

Allison, J. D., dan T. L. Allison. (2005) : Partition Coefficients For Metals In Surface Water, Soil, and Waste. US EPA.

Arbi, Y., \& Aidha, E. R. (2017). Simulation Of Mercury Transport From Gold Mining Activities In Pelawan River, Sarolangun (Vol. 4, pp. 567-571).

Bedient, Philip B., Rifai, Hanadi S., Newell, Charles J. (1999) : Ground Water Contamination: Transport And Remediation : $2^{\text {nd }}$ Edition. Prentice Hall PTR: Upper Saddle River, USA.

Benedini, M. (2011) : Water Quality Models for Rivers and Streams. State of the Art and Future Perspectives. Europian Water 34 : 27-40.

Dinas Kebersihan dan Pertamanan Kota Padang. (2011) : Dokumen Evaluasi Lingkungan Hidup TPA Air Dingin. Padang.

DeVaull, G.E,. Ettinger, R.A., Salanitro, J.P., Gustafson, J.B., (1997) : Benzene toluene, ethylbenzene, and xylenes degradation in vadose zone soils during vapor transport: firstorder rate constans. November 1214 pp. 365-379.
Damanhuri, Enri. (2008) : Diktat Landfiling Limbah, Institut Teknologi Bandung.

Domenico, P. A., and F. W. Schwartz. (1990) : Physical and Chemical Hydrogeology, John Wiley \& Sons, Inc, New York.

Kassenga G. R. \& Mbuligwe S. E. (2009) : Impacts of a Solid Waste Disposal Site on Soil, Surface Water, and Groundwater Quality in Dar es Salaam City, Tanzania. Journal of Sustainable Development in Africa Vol. 10 : 73-94.

Kachiashvili, K., Gordeziani, G., Lazarov, R. \& Melikdzhanian, D. (2009) : Modeling and Simulation of Pollutants Transport in Rivers. Applied Mathematical Modelling 31: 11371-1396

Pidriansy, Qadriana. (2013) : Kajian Pencemaran Air Tanah Dangkal dan Analisis Resiko Kesehatan Manusia Akibat Lindi dari Landfill. Tesis. TL-ITB Bandung

Pinder, George. F., Celia, Michael. Gray, William G. (1981) : Velocity Calculation from Randomly Located Hydraulic Heads. Journal of Groundwater vol. 19 p 262-264

Lü, F., Zhang, H.,Chang, C. H., Lee D. J. He, P. J., Shao L. M. \& Su, A. (2008) : Dissolved Organic Matter and Estrogenic Potential of Landfill Leachate. Chemosphere 72 : 13811386.

Schnoor, J. L. (1996) : Environmental Modeling Fate and Transport of Pollutants in Water, Air, and Soil, New York : John Wiley \& Sons, Inc.

Tong, W., Y. Rong. (2013) : Dominico Spreadsheet Analytical Manual. California Regional Water Quality Control Board, Los Angles. 